\title{
Biological macromolecule chitosan grafted co-polymeric composite: bio-adsorption probe on cationic dyes
}

\author{
Shyam R. Khairkar ${ }^{1}$. Shubham V. Pansare ${ }^{1}$. Amol A. Shedge ${ }^{1}$. \\ Shraddha Chhatre ${ }^{2}$. Dnyaneshwar K. Kulal ${ }^{1}$. Vishwanath R. Patil ${ }^{1}$. \\ Amol V. Pansare ${ }^{1,3}$ (D)
}

Received: 15 June 2021 / Revised: 30 September 2021 / Accepted: 20 October 2021 /

Published online: 5 November 2021

(c) The Author(s) 2021

\begin{abstract}
Chitosan biological macromolecule is a versatile polymer; chemical modification has been carried out that lead to the formation of chitosan grafted polymers composites (Chito-g-PC). We proposed synthesis of six various Chito-g-PC as sorbents for toxic dyes. A novel graft copolymerization method based on radical polymerization with vinyl monomer like acrylic acid, acrylamide, $N$-isopropylacrylamide, methacrylic acid and polyacrylonitrile were utilized in order to address the large amount of swelling at four different $\mathrm{pH}$ buffers solution. The effect of initiator and monomer concentration, time and temperature on $\%$ grafting and $\%$ grafting efficiency were performed. Comparative characterization of Chito and Chito-g-PC were evaluated by SEM, XRD and FTIR, as well as solubility characteristics of the composites were determined by various $\mathrm{pH}$ buffer solution. Cationic toxic dyes Malachite green (MG) and Methylene blue (MB) were selected as the sorbet, and Chito-g-PC were used as biosorbents. Thermodynamic analysis showed that the sorption process was spontaneous and endothermic with an increased randomness. The sorption experiments were realized with six different Chito-g-PC for MG and $\mathrm{MB}$ at various $\mathrm{pH}$.
\end{abstract}

Keywords Bio sorbent - Chitosan biological macromolecule · Acrylic acid · Acrylamide

Shyam R. Khairkar and Shubham V. Pansare have contributed equally to this work.

Vishwanath R. Patil

vishwanathrpatil03@gmail.com

$\triangle$ Amol V. Pansare

amol.pansare@empa.ch

1 Department of Chemistry, University of Mumbai, Mumbai 400098, India

2 National Chemical Laboratory (NCL), Dr. Homi Bhabha Road, Pune 411008, India

3 Composite Group, Mechanical Systems Engineering, Swiss Federal Laboratories for Materials Science and Technology-Empa, 8600 Dübendorf, Switzerland 


\section{Introduction}

Recently various biosorbent materials such as fungal or bacterial biomass and biopolymers are obtained from the natural resources in large quantities [1, 2]. Special attention has been given to polysaccharides such as chitosan, a natural amino polymer [3]. It is clear from the literature that the bio sorption of dyes using chitosan is one of the more frequently reported emerging methods for the removal of pollutants. Chitosan has been investigated by several researchers as a bio sorbent for the capture of dissolved dyes from aqueous solutions [4]. This natural polymer possesses several intrinsic characteristics that make it an effective biosorbent for the removal of color compound. Its use as a bio sorbent is justified by two important advantages: firstly, its low cost compared to commercial activated carbon, and secondly chitosan, derived by deacetylation of the naturally occurring biopolymer chitin, which is the second most abundant polysaccharide after cellulose [5-7].

Dyes are ionic, aromatic organic compounds with structures including aryl rings which have delocalized electron systems. The color of a dye is provided by the presence of a chromophore group. The presence of ionizing groups known as auxochromes results in a much stronger alteration of the maximum absorption of the compound and provides a bonding affinity. Some common auxochrome groups include $-\mathrm{NH}_{3},-\mathrm{COOH},-\mathrm{HSO}_{3}$ and $-\mathrm{OH}[8-10]$.

Chitosan is an amenable molecule and without disturbing degree of polymerization, one can chemically modify this acquiescent polymer, since it provides functional groups as primary amine $\left(-\mathrm{NH}_{2}\right.$ group of $\left.\mathrm{C}_{2}\right)$ and primary $(-\mathrm{OH}$ group of $\mathrm{C}_{6}$ ) as well as a secondary (-OH group of $\mathrm{C}_{3}$ ) hydroxyl groups in its monomers. Hence there are three main probable positions for chemical grafting.

Chitosan-based adsorbents have received a lot of attention for adsorption of dyes. Various modifications of this polysaccharide have been investigated to improve the adsorption properties as well as mechanical and physical characteristics of chitosan. In this paper we discuss chitosan and its Chito-g-PC for application in the removal of dyes from water. Modification of chitosan changes the original properties of this material so that it can be more suitable for adsorption of different types of dyes. Many chitosan derivatives have been obtained through chemical and physical modifications of raw chitosan that includes cross-linking, grafting and impregnation of the chitosan backbone [11-13]. A chemical modification opens way to utilization of chitosan. The grafted composites have biocompatibility, biodegradability and non-carcinogenicity [14]. Keeping in view modified properties of chitosan grafted composite it was thought to study application of prepared composites. Almost all composite have excellent solvent absorptivity due to interstitial spaces and high lipophilicity [15-17]. This property may be utilized for various technical application and drug delivery. The composite have affinity for few metal ions, hence it is studied for removal of toxic metal ion from water samples [18]. In addition to high absorptivity and adsorption tendency for heavy metal ion, the composites are more suitable for removing of poisonous dyes, which are constantly discharged to water and soil from textile and dyes industries, tanneries, solid polymer electrolytes and electroplating industries. [19-23]. 
The adsorption capacity of two water-soluble toxic cationic dyes $\mathrm{MB}$ and $\mathrm{MG}$ have been reported in this research using Chito-g-PC. The swelling ratio and $\mathrm{pH}$ dependent study of Chito-g-PC have also been studied.

\section{Materials and method}

Chitosan (from Sigma Aldrich Mol wt. $22.742 \mathrm{kDa}$ and degree of deacetylation of $75 \%$ ), Acrylic acid (AA, Merck) and acrylamide (AM, Merck) $N$-isopropylacrylamide, methacrylic acid, acrylonitrile, were used after vacuum distillation. Ammonium persulfate (APS, Merck) was used without purification. Methylene bisacrylamide (MBA, Fluka) was used as received.

\section{Polymer composite preparation}

Chito-g-poly (acrylic acid-co-acrylamide), Chito-g-polyacrylamide, Chito-g-polyacrylicacid, Chito-g- $N$-isopropyl acrylamide, Chito-g-poly(methacrylic acid) and Chito-g-Polyacrylonitrile composite were synthesized by free radical mechanisms method by using ammonium per sulphate as indicator [24, 25]. One representative synthesis of Chito-g-poly (acrylic acid-co-acrylamide) is given here in detail (see Figs. 1 and S1).

Chitosan was dissolved in degassed distilled water containing $1 \%$ of acetic acid. $0.50 \mathrm{~g}$ of chitosan was dissolved in $30.0 \mathrm{ml}$ of distilled $1 \%$ acetic acid solution. The reactor was placed in a water bath preset at $60{ }^{\circ} \mathrm{C}$, then $0.10 \mathrm{~g}$ of potassium per sulphate (KPS) as an initiator was added to chitosan solution and was allowed to stir for $10 \mathrm{~min}$ at $60{ }^{\circ} \mathrm{C}$. After adding KPS, $0.5 \mathrm{ml}$ of acrylic acid and $0.5 \mathrm{~g}$ of acrylamide were added simultaneously to the chitosan solution. MBA solution $(0.1 \mathrm{~g}$ in $5 \mathrm{ml}$

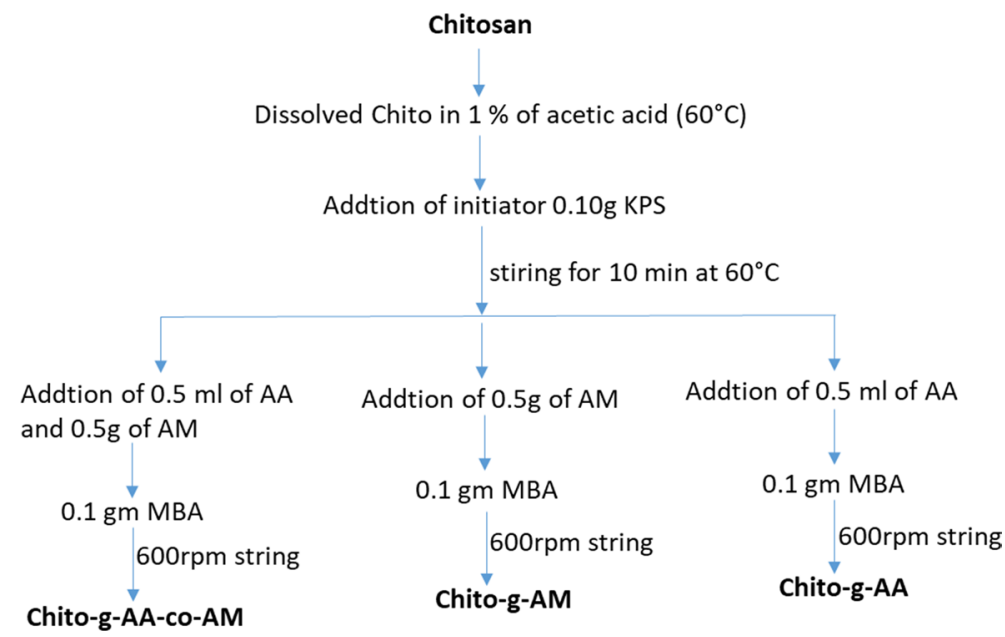

Fig. 1 Schematic diagram/flow chart of synthesis Chito-g-AA-co-AM, Chito-g-AM and Chito-g-AA composites 
$\mathrm{H}_{2} \mathrm{O}$ ) was added to the reaction mixture after addition of monomers and mixture was continuously stirred $(600 \mathrm{rpm})$ for $1.0 \mathrm{~h}$ under nitrogen atmosphere Figure S2 [24].

The swelling properties as well as dyes extraction properties of composites have been studied by preparing synthetic solutions of Chito-g-PC. All samples and stock solution were prepared in distilled water.

The composite with acrylic acid-co-acrylamide, acrylamide, $\mathrm{N}$-isopropylacrylamide were cross-linked with MBA, whereas in the remaining three composites with monomer i.e., acrylic acid, methylmethacrylic acid and acrylonitrile cross linker MBA was not used (Figure S1). The names of composites and their abbreviations shown in Table S1.

\section{Polymer composites characterization}

The structural parameter for Chito-g-PC was further investigated by using Fouriertransform infrared spectroscopy (FTIR), Differential scanning calorimetry (DSC), X-ray diffraction (XRD) and Scanning Electron Microscopy (SEM). The IR spectrum of pure chitosan was used for comparing Chito-g-PC prepared by grafting with various vinyl monomers. In DSC technique amount of heat required to increase temperature of sample and references were measured as a function of temperature. Both sample and reference maintained at nearly same temperature throughout experiment. The glass transition temperature ( $T \mathrm{~g}$ ) of Chito-g-PC were measured by DSC. The change in the chitosan structure after Chito-g-PC were investigated by XRD. The surface morphology and cross section morphology of chitosan and Chito-g-PC were characterized by SEM.

\section{Swelling study of polymer composites}

A Chito-g-PC sample $(0.10 \mathrm{~g})$ was weighed and transferred into tea bag and immersed in $100 \mathrm{ml}$ distilled water and allowed to soak for $2 \mathrm{hrs}$ at room temperature. The equilibrated swollen composite was allowed to drain by removing the tea bag from water and hanging until no drop drained (20 min). The bag was then weighed to determine the weight of the swollen Chito-g-PC. The equilibrium swelling was calculated using the following equation [26].

$$
\text { Material equilibrium swelling ratio }=\frac{\text { weight of dry composite material before swelling }}{\text { Weight of equilibrated composite }}
$$

Swelling ratio (absorbency) was calculated as grams of water per gram of resin $(\mathrm{g} / \mathrm{g})$. The accuracy of the measurements was $\pm 3 \%$. Buffer solution of $\mathrm{pH} 3,5,9$ and 11 were prepared by using respective buffer tablets (Table S2). Dry weight of Chitog-PC were measured and inserted into respective buffer solution and then weight of Chito-g-PC were measured after $2 \mathrm{hrs}$ at ambient temperature and swelling ratio of following Chito-g-PC solution were observed (Fig. 2). 


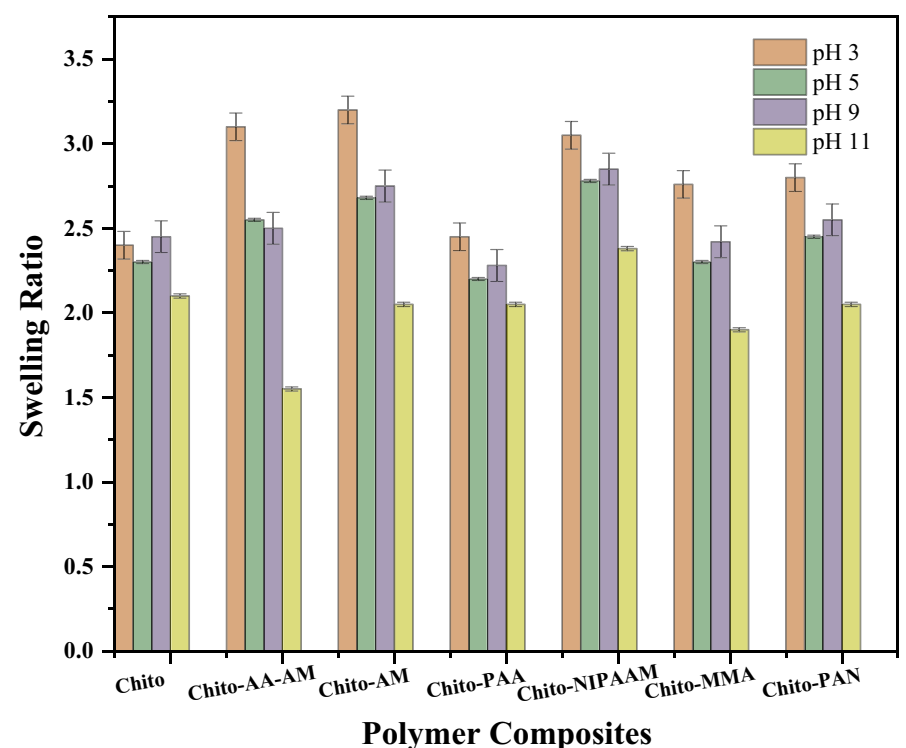

Fig. 2 Swelling behavior of Chito-g-polymer composites with change in $\mathrm{pH}$

\section{Adsorption studies of polymer composites}

A stock solution of MB and MG dyes $(1.0 \mathrm{~g} / \mathrm{L})$ was prepared by dissolving $1 \mathrm{~g}$ of MB and MG dyes powder in $1 \mathrm{~L}$ of double distilled water. The desired concentrations ranging from 10 to $60 \mathrm{mg} / \mathrm{L}$ were obtained by dilution. For each adsorption experiment, $50 \mathrm{ml}$ of the dye solution with a specified concentration was stirred at $100 \mathrm{rpm}$ in a glass flask. The $\mathrm{pH}$ of solutions was adjusted to a desired value by adding $0.1 \mathrm{~mol} / \mathrm{L} \mathrm{NaOH}$ or $\mathrm{HCl}$ solution. $50 \mathrm{mg}$ (Chitosan-g-poly acrylic acidco-acrylamide) composite samples were put into conical flasks, into which $50 \mathrm{~mL}$ aqueous solutions of $\mathrm{MB}$ and MG were added separately and vibrated at $125 \mathrm{rpm}$ in a shaking water bath. When the adsorption reached equilibrium after $12 \mathrm{~h}$, the conical flasks were taken out and centrifuged to separate the composite and the solution. The concentrations of the free dyes in the filtrate were analyzed with a UV-Vis spectrophotometer Lambda 650 (PerkinElmer). In this way batch extraction study were carried out for all chitosan grafted composites i.e., Chitosan-g-polyacrylamide, Chitosan-g-polyacrylic acid, Chitosan-g- $N$-isopropylacrylamide, chitosan-g-poly (methacrylic acid) copolymer and Chitosan-g-Polyacrylonitrile by varying $\mathrm{pH}$.

\section{Result and discussion}

The objective of the present work was to modify chitosan with selected vinyl monomers through free radical graft copolymerization for the development of synthetic natural polymer hybrid materials with defined structures, compositions and 
tailor-made properties. An elaborate physicochemical, thermo-analytical and morphological evaluation of the copolymers were performed using FTIR, DSC, XRD and mechanical property evaluation, swelling studies, SEM studies etc. As Chitosan is second most abundant polysaccharide on earth which gives a green route for metal extraction. The study throws some light on the prospects of synthetic protocols that can be adopted to realize chitosan-g-vinyl polymers with controlled extent of grafting and nature of graft. As a general conclusion, the objective of the study to synthesize natural-synthetic hybrid materials with tailor-made properties has been achieved through the copolymerisation of chitosan with the selected vinyl monomers like AA, AM, NIPAAM, MA and PAN.

\section{Polymer composites characterization}

\section{FTIR studies}

The main characteristic peaks in chitosan spectrum were observed at $3455 \mathrm{~cm}^{-1}$ (O-H stretch, N-H stretch, overlapped), $2922 \mathrm{~cm}^{-1}$ and $2871 \mathrm{~cm}^{-1}$ (C-H stretch), $1656 \mathrm{~cm}^{-1}\left(\mathrm{NH}_{2}\right.$ deformation), $1620 \mathrm{~cm}^{-1}$ (N-H bend), $1327 \mathrm{~cm}^{-1}$ (C-N stretch), $1155 \mathrm{~cm}^{-1}$ (bridge $-\mathrm{O}-$ stretch), and $1092 \mathrm{~cm}^{-1}$ (C-O stretch). In the spectrum of grafted chitosan, addition to the chitosan characteristic peaks, some new absorption peaks were appeared (Figure S3).

Chito-g-AA-co-AM composite showed broad band at $3342 \mathrm{~cm}^{-1}$ which corresponds to $\mathrm{O}-\mathrm{H}$ and amide (-NH) groups stretching. The small peak at $2921 \mathrm{~cm}^{-1}$ accredited to the asymmetric stretching frequency of $-\mathrm{CH}$ group, while peak at $1658 \mathrm{~cm}^{-1}$ was assigned for $\mathrm{N}-\mathrm{H}$ deformation bending of backbone (Figure S4). A very intense characteristic band at $1665 \mathrm{~cm}^{-1}$ was observed due to $\mathrm{C}=\mathrm{O}$ asymmetric stretching in carboxylate anion and was reconfirmed by peak at $1449 \mathrm{~cm}^{-1}$. Chito-g-AA-co-AM, showed two additional peaks at $1726 \mathrm{~cm}^{-1}$ (carboxylic acid) and $1564 \mathrm{~cm}^{-1}$ (amide) which were absent in the IR spectrum of pure chitosan, this clearly indicates the formation of graft copolymer [27]. FTIR spectrum of Chito-g-AM composite showed two peaks at $3206 \mathrm{~cm}^{-1}$ and $1660 \mathrm{~cm}^{-1}$ corresponding to the primary amides and amide $-\mathrm{NH}$ stretching vibrations. Polyacrylamide can be identified by its characteristic amide $\mathrm{C}=\mathrm{O}$ peak at $1660 \mathrm{~cm}^{-1}$, which is also present in the spectrum of Chito-g-PAM. Chito-g-AA - The peak at $1735 \mathrm{~cm}^{-1}$ corresponds to the carboxyl absorption from grafted acrylic acid and the peaks at $821 \mathrm{~cm}^{-1}$ and $619 \mathrm{~cm}^{-1}$ were characteristic absorptions of acrylic acid. Chito-g-NIPAAM-The FTIR spectrum of chitosan with a $75 \%$ deacetylation degree indicated that peaks appeared at $3436 \mathrm{~cm}^{-1}$ (corresponding to $\mathrm{OH}$ stretching vibration, which indicated a chemical reaction between chitosan and $\mathrm{N}$-isopropylacrylamide), $1658 \mathrm{~cm}^{-1}$, and $1569 \mathrm{~cm}^{-1}$ could be assigned to a hydroxyl group, carbonyl stretching vibration (amide I), and $\mathrm{N}-\mathrm{H}$ bending vibration (amide II) of a primary amino group, respectively. Chito-gPMMA- The intense band at $3423 \mathrm{~cm}^{-1}$ was assigned to the stretching vibrations of O-H group. The absorption bands at $1154 \mathrm{~cm}^{-1}$ and $1033 \mathrm{~cm}^{-1}$ were assigned for asymmetric stretching of the $\mathrm{C}-\mathrm{O}-\mathrm{C}$ bridge. Chito-g-PAN- FTIR studies showed 
that peak of chitosan at $1164 \mathrm{~cm}^{-1}$ disappeared indicating that this peak may be hindered by cross-linking. When crosslinker was used, FTIR showed appearance of new peak at $1550 \mathrm{~cm}^{-1}$ which can be attributed to cross-linking reaction of chitosan with cross-linking monomer. A new sharp peak appeared at $1627 \mathrm{~cm}^{-1}$ suggested, the stretching of $\mathrm{N}=\mathrm{C}$ in composite form by the reaction of graft copolymerization. A band at $1564 \mathrm{~cm}^{-1}$ indicated involvement of $-\mathrm{NH}_{2}$ group during grafting.

\section{DSC studies}

DSC is the best analytical technique to find the polymer crystallinity, which measures the physical nature of the sample. In this technique a sample is heated or cooled at linear intervals of temperature and the particular temperature and energy accompanied with any one of the range of thermal events is measured. It was observed from DSC plot that chitosan undergoes dehydration at lower temperature as compared to Chito-g-PC. However loss of water from composite was steady and periodic which showed that dehydration pattern was regular in case of DSC of chitosan (Figure S5). DSC of Chito-g-PC showed a weight loss in two distinct stages. The first stage ranges between 205 and $246{ }^{\circ} \mathrm{C}$ and showed about $42 \%$ loss in weight corresponding to the loss of adsorbed and bound water. This confirms that water does acts as plasticizer at $85{ }^{\circ} \mathrm{C}$ in chitosan and its composites. Water forms an intermolecular hydrogen bonding with Chito-g-PC through amine and hydroxyl groups present in them. This helps in molecular rearrangement that eases the chain mobility in Chito-g-PC.

\section{SEM studies}

The surface morphology and cross section morphology of Chito-g-polymer composites were characterized by SEM (Figure S6). The SEM micrograph Chito-g-AACo-AM, Chito-g-AA, Chito-g-AM, Chito-g-NIPAAM and Chito-g-PAN showed that it was porous structure with many spaces between layers, which may be due to presence of water molecules beneath the region. Interaction between chitosan matrix and monomer may be leading to hydrogen bonding in formation of composites. This develops fine pores and micro voids. The porous structure supports the permeation and interface site of external stimuli with hydrophilic group of Chito-g-polymer composites. Porous morphology of Chito-g-PMMA was slightly different from other Chito-g-polymer composite. It concluded that all composite have porous structure with intermolecular spaces. The size of pore and intermolecular spaces varies depending upon grafted monomer. The pore distribution of composite was comparatively regular. The composites showed high adsorbing surface and high equilibrium adsorption capacity.

\section{XRD studies}

Diffraction studies of all synthesized composites revealed the strong interaction between chitosan and the Chito-g-PC as indicated by broad amorphous peak for the entire composites, composites showed $2 \theta$ values at $21.44^{\circ}, 22^{\circ}$, 
$22.62^{\circ}, 22.60^{\circ}, 21.76$ and $21.96^{\circ}$. Characteristic crystalline peaks reflection $2 \theta$ at $19.34^{\circ}$ corresponds to orthorhombic crystal structure of chitosan (Figure S7). The strong intermolecular hydrogen bonding introduced certain regularity in the crystal but composite tends to be more amorphous than pure chitosan. DSC studies revealed that crystalline structure gets converted to amorphous after glass transition point. XRD of pure chitosan and Chito-g-PC showed that crystallinity of chitosan decreases after modification. Similarly shifting in diffraction pattern $\left(\sim 19^{\circ}\right.$ to $\left.\sim 21-22^{\circ}\right)$ of pure chitosan and composites confirmed extensive cross-linking.

\section{Swelling study of polymer composites}

The swelling study revealed that the Chito-g-PC were having variable swelling behavior in different $\mathrm{pH}$ solutions which contributed to effect on swelling. This indicated that the Chito-g-PC phase transition was well affected $\mathrm{pH}$ environment which make it favorable for metal and dyes extraction properties (Fig. 2) [28].

\section{Adsorption studies}

Adsorption of MG and MB from aqueous solution was tested in batch experiments. Batch adsorption experiments were carried out to examine effects of adsorbent dosage, initial dye concentration, solution $\mathrm{pH}$, and time on the adsorption of $\mathrm{MG}$ and $\mathrm{MB}$ on chitosan. Effects of the dye concentrations, $\mathrm{pH}$ of the medium, and contact time on the adsorption and capacity were studied and the sorption kinetics was also evaluated [29]. The amount adsorbed was calculated based on the difference of the dye concentrations and the weight of the modified microspheres by the following equation;

$$
A=\frac{(C i-C e) V}{W}
$$

where $A$ is the amount of dyes adsorbed onto unit amount of the sorbents $(\mathrm{mg} / \mathrm{g})$, $C i$ is the initial dye concentration $(\mathrm{mg} / \mathrm{L}), C e$ is the equilibrium dye concentration $(\mathrm{mg} / \mathrm{L}), V$ is the volume of dye solution (L), and $W$ is the dry weight of the adsorbents. The adsorption temperature was $25^{\circ} \mathrm{C}$. The initial dyes concentration was $500 \mathrm{mg} / \mathrm{L}$ for each MB and MG, respectively. For adsorption experiments, the concentration ranges used were 50-650 and 50-400 $\mathrm{mg} / \mathrm{L}$ for both MB and MG, respectively (Fig. 3).

The effects of the $\mathrm{pH}$ of the sample solutions on the adsorption of dyes evaluated by adjusting the $\mathrm{pH}$ by $\mathrm{HCl}$ and $\mathrm{NaOH}$. The effect of initial $\mathrm{pH}$ on biosorption percentages of dyes were examined over a range of $\mathrm{pH}$ values from 2 to 11 for $\mathrm{MB}$ and MG (Fig. 4). The dye adsorption for MG were minimum at the initial $\mathrm{pH}$ 2. The dyes sorption increased with the increase in the initial $\mathrm{pH}$ from $\mathrm{pH} 2-11$ in $\mathrm{MB}$ and MG. The solution $\mathrm{pH}$ affected the activity of the functional groups (carboxyl) as well as the competition of cationic dyes for the binding sites. At lower $\mathrm{pH}$ value, the composite surface became more positively charged, thus increasing the electrostatic 


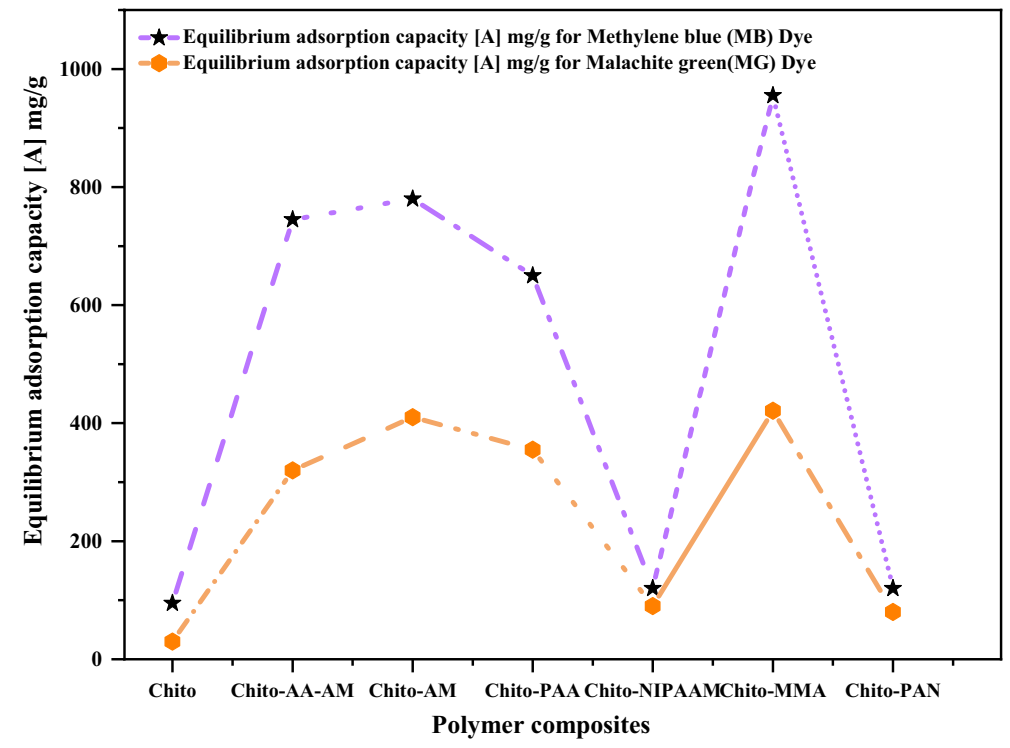

Fig. 3 Equilibrium adsorption capacity of MG and MB dyes for polymer composites

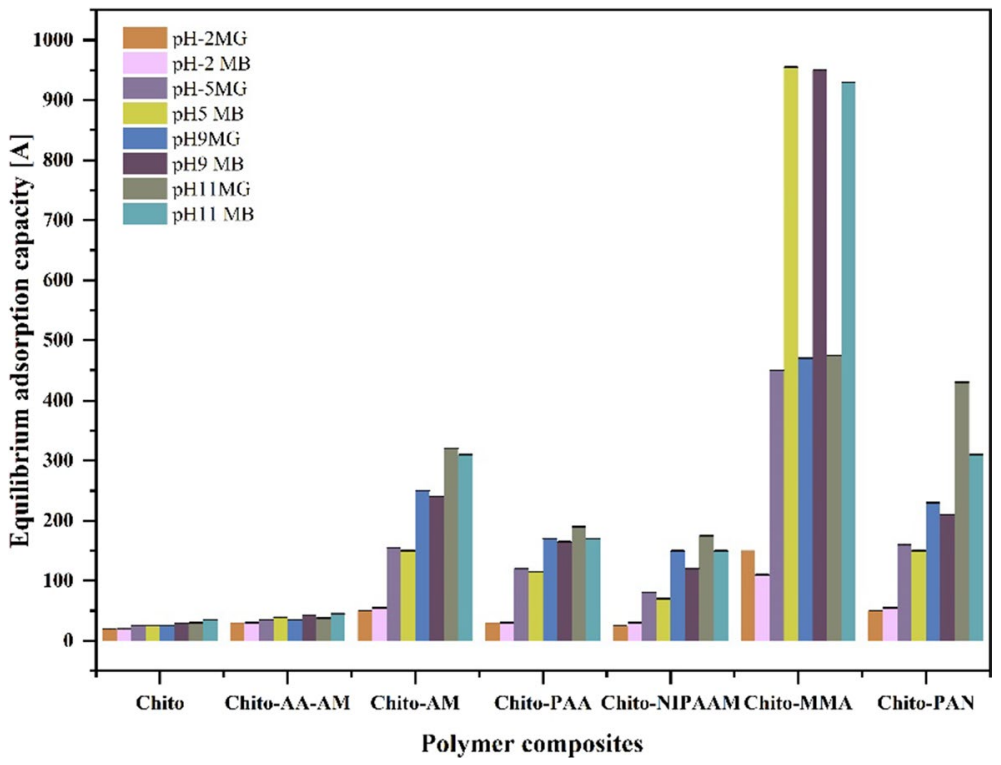

Fig. 4 Equilibrium adsorption capacity [A] mg/g for Malachite green (MG) and Methylene Blue (MB) dyes at varying $\mathrm{pH}$

repulsive force between the modified Chito-g-PC and cationic dyes. In contrast, as the $\mathrm{pH}$ value increased, the composite surface was more negatively changed, which promoted the uptake on the modified Chito-g-PC. 


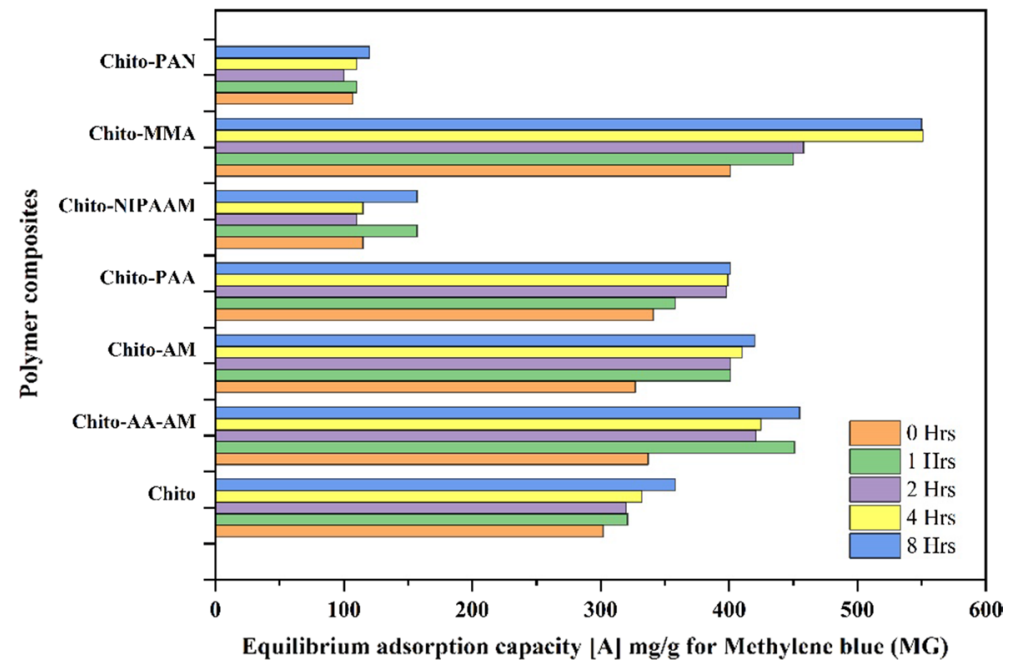

Fig. 5 Effects of the dye concentrations and contact time on the adsorption Capacity (A) for MG Dye

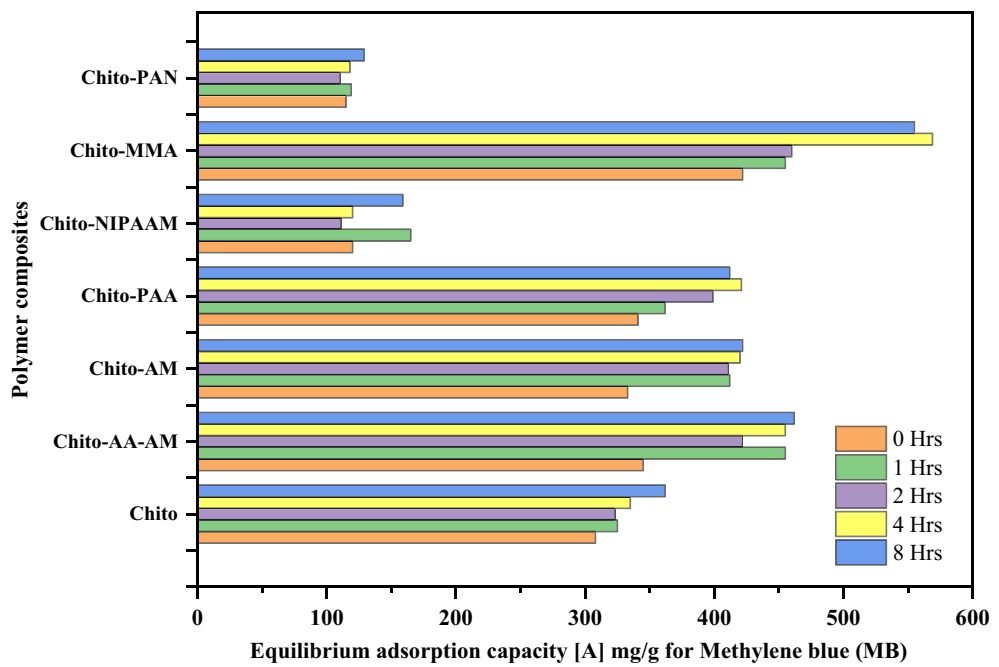

Fig. 6 Effects of the dye concentrations and contact time on the adsorption capacity (A) for MB Dye

\section{Effects of the MG and MB concentrations and contact time on the adsorption capacity $[A]$}

The adsorption of MG and MB from aqueous solution by newly synthesized Chitog-PC were investigated and shown in Figs. 5 and 6. The percentage adsorptions of dyes on adsorbent were determined by batch methods using UV-Vis spectrophotometer Lambda 650 (PerkinElmer). The effect of experimental parameters, such as $\mathrm{pH}$, treatment time, temperature, adsorbent dose, initial dyes concentration on the 
removal of dyes were also studied. All Chito-g PC were studied for their cationic dyes properties in terms of Equilibrium Absorption Capacity (A). The initial dye concentration was $500 \mathrm{mg} / \mathrm{L}$ for $\mathrm{MG}$ and $\mathrm{MB}$. The adsorption mechanisms of MG and $\mathrm{MB}$ on surface of composites is described in Fig. 7, as amide from chitosan form strong co-ordinate bond with dyes and were adsorbed on surface chemically.

\section{Thermodynamic parameters}

Spontaneity of a process can be determined by thermodynamic parameters such as enthalpy change $\left(\Delta H^{\circ}\right)$, free energy change $\left(\Delta G^{\circ}\right)$ and entropy change $\left(\Delta S^{\circ}\right)$. A spontaneous process will show a decrease in $\Delta G^{\circ}$ and $\Delta H^{\circ}$ values with increasing

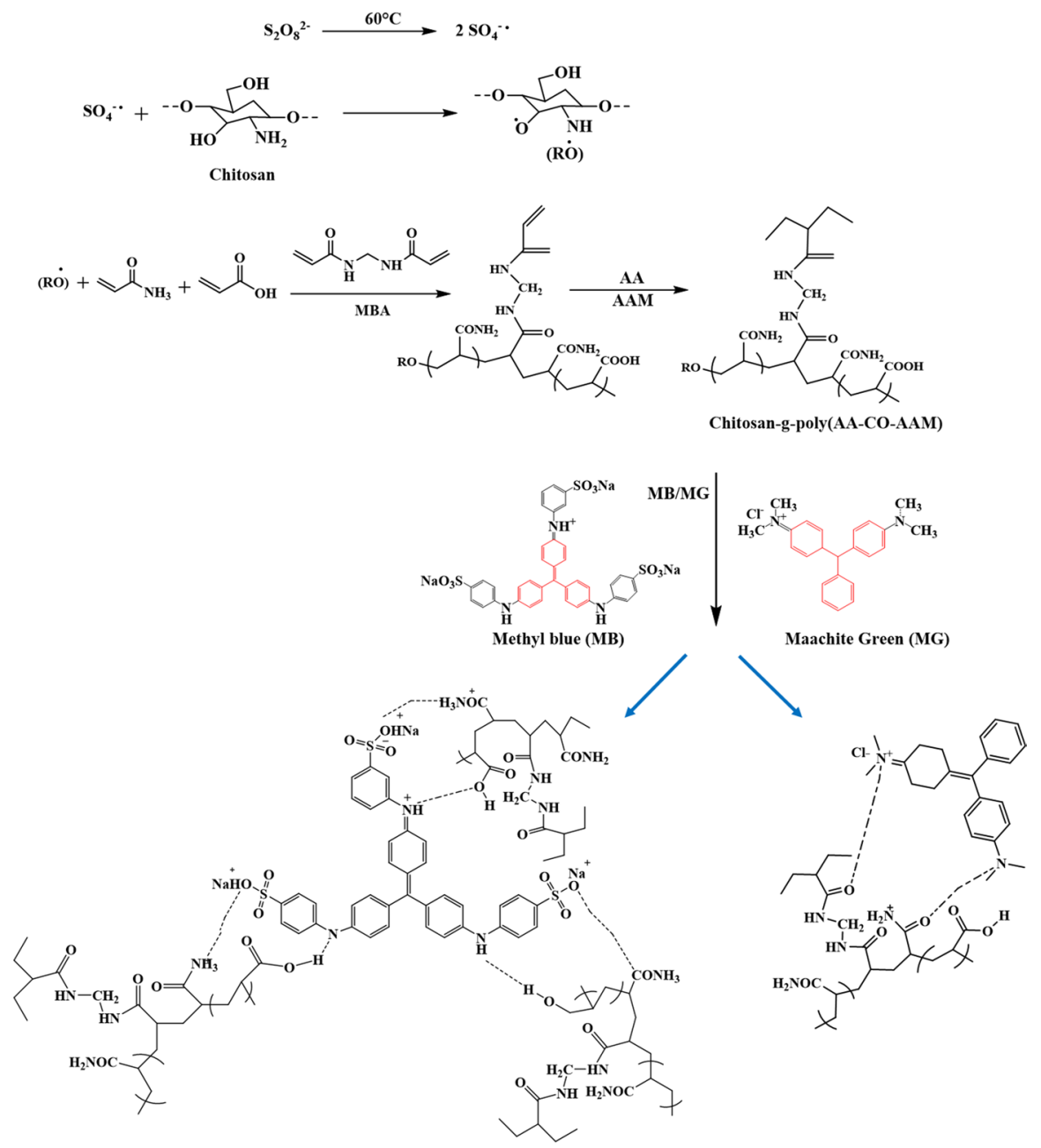

Fig. 7 Adsorption mechanisms of MG and MB dye on surface of composites 
temperatures [30-33]. The temperatures used in the thermodynamic study were 300 and $310 \mathrm{~K}$. The thermodynamic parameters were calculated based on the following equations:

$$
\Delta G^{\circ}=\Delta H^{\circ}-T \Delta S^{\circ}
$$

Table 1 lists down the values for the thermodynamic parameters. The positive value for the enthalpy change, $\Delta H^{\circ}(13.10 \mathrm{~kJ} / \mathrm{mol})$, indicated the endothermic nature of the adsorption and explains the increase in $\mathrm{MG}$ and $\mathrm{MB}$ adsorption efficiency as the temperature increased. The positive value for the entropy change, $\Delta S^{\circ}(121.91 \mathrm{~J} /$ mol K), indicated that there was an increased disorder at the solid/liquid interface during MG and MB adsorption onto the modified chitosan. The negative value for the free energy change, $\Delta G^{\circ}$, implies the spontaneity of the adsorption process, which does not require an external energy source for the system.

\section{Adsorption mechanisms of dye on surface of polymer composite}

MB and MG poses three binding site to form co-ordinate bond with grafted composite. There was strong co-ordinate interaction between $\left(-\mathrm{CONH}_{2}\right.$ of grafted composite and $-\mathrm{SO}_{3} \mathrm{Na}$ end of dye molecule) hence dyes molecule gets absorbed on surface of sorbent by coordinate interaction (Fig. 7).

\section{Reusability of polymer composite}

The growing interest in chemical modification of chitosan to improve their solubility and applications requires structural analysis of modified form of chitosan. Degree of deacetylation is one of the most important chemical parameters which affects physicochemical properties of chitosan. Reusability of the modified Chito-g-polymer composite were one of the most important parameters determining the cost effectiveness of the developed method. The recovery of the MB and MG dyes for all the adsorbents were achieved by eluting an appropriate amount of distilled water at various $\mathrm{pH}$. The desorption efficiency of respective dyes were achieved in the said time period for the Chito-g-PC. MB adsorption-desorption shows $98.76 \%$ from Chito-g$\mathrm{PC}$, minimal decrease in adsorption-desorption performance was noted even after eight cycles for MB. Whereas for MG, 97.87\% adsorption-desorption from Chito-gPC was revealed, slightly decreasing elution performance after seven cycles. Therefore, the evaluated data for both dyes implies that adsorption-desorption percentage decreased slightly by the increase in cycles number.

Table 1 Thermodynamic parameters

\begin{tabular}{cllll}
\hline Dyes & Temperature $(\mathrm{K})$ & $\Delta G \mathrm{KJ} / \mathrm{mol}$ & $\Delta H \mathrm{KJ} / \mathrm{mol}$ & $\Delta S \mathrm{~J} / \mathrm{mol}$ \\
\hline MB & 330 & -22 & 7.54 & 112.44 \\
MB & 330 & -31 & 7.54 & 112.45 \\
MG & 310 & -25 & 7.21 & 128.3 \\
MG & 310 & -32 & 7.22 & 128.3 \\
\hline
\end{tabular}




\section{Conclusion}

Chitosan based adsorbents have received a lot of attention for adsorption of dyes. Various modifications of this polysaccharide have been investigated to improve the adsorption properties as well as mechanical and physical characteristics of chitosan. Modification of chitosan changes the original properties of this material so that it can be more suitable for adsorption of different types of dyes. In the present investigation novel, environmentally-friendly Chito-g-PC, namely, Chito-g-(AA-coAM), Chito-g-AM, Chito-g-PAA, Chito-g-NIPAM, Chito-g-PMMA and Chito-gPAN were prepared by homogeneous grafting by free radical mechanisms. These composites showed higher swelling ratio at $\mathrm{pH} 5$ and Chito-g-(AA-co-AM) showed maximum swelling than other composites at acidic $\mathrm{pH}$. Chito-g-MA composite showed higher sorption capacities than other all composites selectively for MG and $\mathrm{MB}$ at acidic $\mathrm{pH}$. Adsorption studies of Chito-g-PMAA for MG and MB showed endothermic behavior. The previous findings indicated that a feasible solution to the drawback of the high degree of swelling of Chito-g-(AA-co-AM) derivatives was devised by other Chito-g-PC. But all those Chito-g-PC can shows metal extraction behavior which could be new horizon in field of biochemistry. In particular, Chitog-PMAA has all of the sorption characteristics of effective application in large-scale implementations for cationic dye removal from aqueous solutions.

Supplementary Information The online version contains supplementary material available at https://oi. org/10.1007/s00289-021-03954-w.

Acknowledgements A.V.P. acknowledges Composites Group, Mechanical Systems Engineering, Swiss Federal Laboratories for Materials Science and Technology-Empa, 8600 Dübendorf, Switzerland for funding. All authors acknowledges Mr. Chandan Warkar, Promas Pharma Ltd., Mumbai, India, for XRD Analysis facility.

Author contributions SRK and SVP authors contributed equally to this work.

Funding Open Access funding provided by Lib4RI - Library for the Research Institutes within the ETH Domain: Eawag, Empa, PSI \& WSL.

\section{Declarations}

Conflict of interest There are no conflict to declare.

Open Access This article is licensed under a Creative Commons Attribution 4.0 International License, which permits use, sharing, adaptation, distribution and reproduction in any medium or format, as long as you give appropriate credit to the original author(s) and the source, provide a link to the Creative Commons licence, and indicate if changes were made. The images or other third party material in this article are included in the article's Creative Commons licence, unless indicated otherwise in a credit line to the material. If material is not included in the article's Creative Commons licence and your intended use is not permitted by statutory regulation or exceeds the permitted use, you will need to obtain permission directly from the copyright holder. To view a copy of this licence, visit http://creativecommons.org/licen ses/by/4.0/. 


\section{References}

1. Kulal DK, Pansare AV, Tetgure SR, Karve M, Patil VR (2016) Determination of uranium(VI) using Penicillium chrysogenum immobilized on silica gel and spectrophotometer. J Radioanal Nucl Chem 307:1253-1263

2. Kulal DK, Pansare AV, Shedge AA, Patil VR (2016) Fungal strain of aspergillus oryzae immobilized on silica gel for Au(III) sorption. Eur Chem Bull 5(6):225-231

3. Forgacs E, Cserhati T, Oros G (2004) Removal of synthetic dyes from wastewaters: a review. Environ Int 30:953-971

4. Synowiecki J, Al-Khateeb NA (2003) Production, properties, and some new applications of chitin and its derivatives. Crit Rev Food Sci Nutrition 43:145-71

5. Struszczyk MH (2002) Chitin and chitosan-part I. Properties and production. Polimery 47:316-325

6. Rinaudo M (2006) Chitin and chitosan: properties and applications. Prog Polym Sci 31:603-632

7. Nagarkar AA, Kilbinger AFM (2014) End functional ROMP polymers via degradation of a ruthenium Fischer type carbine. Chem Sci 5:4687-4692

8. Pokhrel D, Viraraghavan T (2004) Treatment of pulp and paper mill wastewater-a review. Sci Total Environ 333:37-58

9. Thompson G, Swain J, Kay M, Forster CF (2001) The treatment of pulp and paper mill effluent: a review. Bioresour Technol 77:275-286

10. Aksu Z (2005) Application of biosorption for the removal of organic pollutants: a review. Process Biochem 40:997-1026

11. Zhang S, Dong Y, Yang Z, Yang W, Wu J, Dong C (2016) Adsorption of pharmaceuticals on chitosan-based magnetic composite particles with core-brush topology. Chem Eng J 304:325-334

12. Mahdavinia GR, Pourjavadi A (2004) Modified chitosan Superabsorbent hydrogels from poly(acrylic acid-co-acrylamide) grafted chitosan with salt and $\mathrm{pH}$ responsiveness properties. Eur Polym J 40:1399-1407

13. Babaladimath G, Chapi S (2018) Microwave-assisted synthesis, characterization of electrical conducting and electrochemical xanthan gum-graft-polyaniline. J Mater Sci: Mater Electron 29:11159-11166

14. Chapi S (2020) Structural and electrochemical properties of polymer blend based $\mathrm{ZnO}$ nanocomposite solid polymer electrolytes by spin-coating method. J Nano- Electron Phys 12(2):02043(1)-02043(5)

15. Tan EKW, Shrestha PK, Pansare AV, Chakrabarti S, Li S, Chu D, Lowe CR, Nagarkar AA (2019) Density modulation of embedded nanoparticles via spatial, temporal, and chemical control elements. Adv Mater 31:1901802

16. Pansare AV, Khairkar SR, Shedge AA, Chhatre SY, Patil VR, Nagarkar AA (2018) In Situ nanoparticle embedding for authentication of epoxy composites. Adv Mater 30:1801523

17. Pansare AV, Chhatre SY, Khairkar SR, Bell JG, Barbezat M, Chakrabarti S, Nagarkar AA (2020) "Shape-coding": morphology-based information system for polymers and composites. ACS Appl Mater Interfaces 12(24):27555-32756

18. Akkaya R, Ulusoy U (2008) Adsorptive features of chitosan entrapped in polyacrylamide hydrogel for $\mathrm{Pb}^{2+}, \mathrm{UO}_{2}{ }^{2+}$, and $\mathrm{Th}^{4+}$. J Hazard Mater 151:380-388

19. Galhoum AA, Mafhouz MG, Gomaa NA, Abdel-Rehem SS, Atia AA, Vincent T, Guibal E (2015) Cysteine-functionalized chitosan magnetic nano-based particles for the recovery of uranium(vi): uptake kinetics and sorption isotherms. Sep Sci Technol 50:2776-2789

20. Pansare AV, Shedge AA, Chhatre SY, Das D, Murkute P, Pansare SV, Nagarkar AA, Patil VR, Chakrabarti S (2019) AgQDs employing black box synthetic strategy: photocatalytic andbiological behavior. J Lumin 212:133-140134

21. Pansare AV, Kulal DK, Shedge AA, Patil VR (2016) hsDNA groove binding, photocatalytic activity, and in vitro breast and colon cancer cell reducing function of greener SeNPs. Dalton Trans 45:12144-12155

22. Chapi S (2020) Optical, electrical and electrochemical properties of PCL5/ITOtransparent conductivefilms deposited by spin-coating-materials forsingle-layer devices. J Sci: Adv Mater Dev 5:322-329

23. Chapi S (2021) Influence of $\mathrm{Co} 2+$ on the structure, conductivity, and electrochemical stability of poly(ethylene oxide)-based solid polymer electrolytes: energy storage devices. J Electron Mater 50(3):1558-1571 
24. Mahdavinia GR, Pourjavadi A (2004) Modified chitosan Superabsorbent hydrogels from poly(acrylic acid-co-acrylamide) grafted chitosan with salt- and $\mathrm{pH}$-responsiveness properties. Eur Polym J 40:1399-1407

25. Salam OEA, Reiad NA, ElShafei MM (2011) A study of the removal characteristics of heavy metalsfrom wastewater by low-cost adsorbents. J Adv Res 2(4):297-303

26. Sadeghi M, Yarahmadi M (2011) Synthesis of a novel $\mathrm{pH}$ - and salt-responsive super absorbent hydrogel based on collagen-g-poly(AA-co-IA). Orient J Chem 27:453

27. Kumar D, Raj V, Verma A, Kumar P, Pandey J (2019) Novel binary grafted chitosan nanocarrier for sustained release of curcumin. Int J Biol Macromol 131:184-191

28. Crini G, Badot P-M (2008) Application of chitosan, a natural aminopolysaccharide, for dye removal from aqueous solutions by adsorption processes using batch studies: a review of recent literature. Prog Polym Sci 33:399-447

29. Ohto K, Inoue S, Eguchi N, Shinohara T, Inoue K (2002) Adsorption behavior of lead ion on calix [4] arenetetracarboxylic acid impregnated resin. Sep Sci Technol 37(8):1943-1958

30. Pansare AV, Kulal DK, Shedge AA, Patil VR (2016) Green synthesis of anticancerous honeycomb PtNPs clusters: theiralteration effect on BSA and HsDNA usingfluorescence probe. J Photoch Photobiol B 162:473-485

31. Saha TK, Bhoumik NC, Karmaker S, Ahmed MG, Ichikawa H, Fukumori Y (2010) Adsorption of methyl orange onto chitosan from aqueous solution. J Water Resource Protection 2:898-906

32. Pansare AV, Shedge AA, Patil VR (2018) Discrete SeNPs-macromolecule binding manipulated by hydrophilic interaction. Int J Biol Macromol 107:1982-1987

33. Shedge AA, Pansare SV, Khairkar SR, Chhatre SY, Chakrabarti S, Nagarkar AA, Pansare AV, Patil VR (2020) Nanocomposite of functional silver metal containing curcumin biomolecule model systems: protein BSA bioavailability. J. Inorg. Biochem 212:111210

Publisher's Note Springer Nature remains neutral with regard to jurisdictional claims in published maps and institutional affiliations. 